\title{
MONITORING FRACTURE TOUGHNESS USING \\ MINIATURE SAMPLES
}

S.D. NORRIS and J.D. PARKER

Department of Materials Engineering, University College, Swansea SA2 8PP

\section{ABSTRACT}

This paper describes the development of a miniaturised disk test technique capable of measuring load-displacement and fracture properties. Reproducible data have been produced over a wide range of conditions for a normalised and tempered low alloy steel. As the test temperature was reduced, a transition in failure mode from ductile to brittle rupture occurred. Fractographic studies have been performed to evaluate the behaviour through this transition.

\section{INTRODUCTION}

To prevent catastrophic failure of high energy components, design approaches involve structura integrity assessment. These assessments consider loading conditions, material properties and the presence of defects. Typically the appropriate component stresses are determined from established analytical techniques, with the size and location of defects estimated using non-destructive testing procedures. Measurement of appropriate properties also can be performed following fabrication since batches of representative material should be available. In general, the necessary meteria characterisation involves tensile testing to establish modulus, yield stess, ultimate strength ductility, also assessment of fracture toughness by compact tension and/or Charpy impact testing.

Since many industrial installations operate for periods up to and even exceeding 30 years, it is frequently necessary to repeat an assessment of structural integrity at appropriate intervals. Any changes in loading conditions can usually be adequately evaluated using the same analysis involved during design. Furthermore, in the majority of situations, repeated non-destructive testing can be carried out to ensure that defects have not developed. However, a major difficulty in undertaking this type of assessment arises because of uncertainty regarding appropriate material properties. This will be a particular problem in facilities that operate at elevated temperatures, since, in many cases the materials of construction are susceptible to time dependent changes in properties, eg reductions in fracture properties may occur due to temper embrittlement ${ }^{[1]}$. Thus, for these components, realistic assessments require that additional tests are performed to measure actual properties. Problems may then be encountered since standard procedures for tensile or fracture testing require relatively large specimens. In some cases the component geometry may be insufficient for the manufacture samples with the appropriate geometry. Furthermore, even when component dimensions would all the fabrication of relatively large test pieces, the act of material reval and be deleterious to continued operation, either by modifying the properties and or due may development of welding residual stresses. Thus, in many cases stre propertes and/or due to the service can only be estimated based on assumed properties.

The process of assuming properties is clearly unsatisfactory. If the assumptions are too conservative components will be replaced unnecessarily, alternatively if too little change is considered,
catastrophic failure may occur. The ability to measure actual properties from plant without affecting catastrophic failure may occur. The ability to measure actual properties from plant without affecting future service performance is therefore vital to accurate condition assessment. Recently significan advances have heen made in techniques for the removal of material samples. Thus, equipment has een developed which will allow the removal of button shaped samples in an effectively non- 
Charpy impact tests were performed on standard notched bars to evaluate fracture behaviour over a range of temperature. The bars were taken from the pipe such that their orientation was the over as that of the disks. Duplicate tests were performed at six test temperatures from $-32^{\circ} \mathrm{C}$ to $+140^{\circ} \mathrm{C}$ Heating and cooling media such as a sand bath, hot water and ice were used to achieve the $140 \mathrm{C}$. temperatures. The results produced, were in the form of fracture energies, measured in joules. Post test examination was performed to estimate the percentage of observable ductility on joch frast surfaces. Plots of fracture energy and \% ductility versus temperatie were product $50 \%$ fracture appearance transition temperature $(50 \% \mathrm{FATT})$

Fractured disk test specimens from the complete test temperature range, were prepared, cleaned in an ultrasonic bath, and examined using a Jeol scanning electron microscope. Detailed examination was also performed on sets of samples tested under nominally identical conditions.

\section{RESULTS}

The results from the disk test program are presented and analyzed in the following section.

\section{Load Vs. displacement behaviour}

Tests were performed at selected test temperatures over the range $-196^{\circ} \mathrm{C}$ to $+25^{\circ} \mathrm{C}$. The load:displacement data observed showed that the pattern of results changed as the test temperature was reduced. Thus at relatively high temperatures, above about $-110^{\circ} \mathrm{C}$ yielding was followed by a significant period of deformation until eventually a maximum gradually decreased until failure occurred. Typical curves for four room temperature tests are shown in Figure 1a. Clearly the same general pattern of behaviour was observed in each test. Furthermore, the reproducibility of specific results was good, ie the yield load was about $0.194 \mathrm{kN}$ in each case, with the ultimate load and displacement to failure being 0.95 to $1.18 \mathrm{kN}$ and 1.35 to $1.70 \mathrm{~mm}$ respectively. In tests at low temperature the yield load increased and the level of deformation decreased compared to the room temperature results. Indeed as shown in Figure $1 \mathrm{~b}$ at $196^{\circ} \mathrm{C}$ little plastic deformation was measured with failures occurring close to the yield region. Thus these tests the total deformation was about $0.6 \mathrm{~mm}$ with values of yield $0.6 \mathrm{kN}$ and $0.8 \mathrm{kN}$ respectively. Between these limits a transitional patem of loaddispen results was observed.

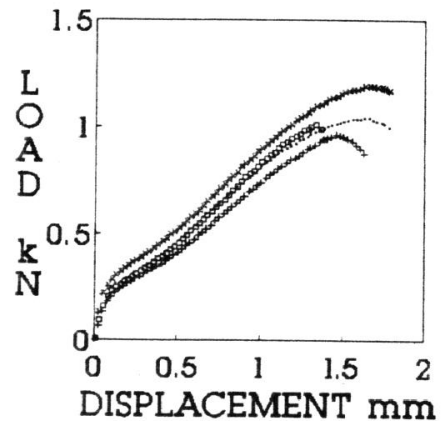

(a)

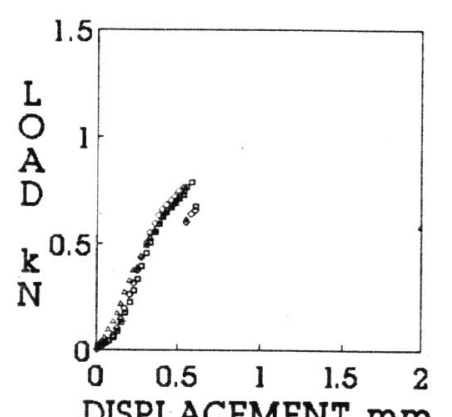

(b) f the dist alignment of the punch at the centre disk thickness.

Figure 1. Variation of load-displacement behaviour for four tests performed at $+25^{\circ} \mathrm{C}($ a) and three tests performed at $-196^{\circ} \mathrm{C}(\mathrm{b})$. 


\section{Fracture surface studies}

The fractured Charpy V-notch specimens were examined macroscopically to estinate of ductile fracture. In general, the broken specimens exhibited a ductile region directly behind the notch, ductile fracture then changed to brittle fracture at a point on the fracture surface that the dependent on the test temperature. It was found that at low test temperatures ie below that was percentage of ductility observed behind the notch was below $15 \%$. A gradual ie below $0{ }^{\circ} \mathrm{C}$ the and conversely decrease in brittleness occurred was below $15 \%$. A gradual increase in ductility $00 \%$ ductility was observed.

Details of the fracture behaviour of the disk samples were established using the scanning electron tud studying the ege invariably started on the bottom surface of the disk. However, the position that cracking erew - $180 \mathrm{C}$, cracking started in the of the punch and propagated radially, as well as through the disk, middle of the disk under the centre At temperatures above $-120^{\circ} \mathrm{C}$ the cracking initiated cirume edge of the spherical punch. This circular rith completely ductile. Between these temperatures a continued to deform with the final failure being two situations was observed.

bserved, with ductility on each fracture surface was recorded. Below $-180^{\circ} \mathrm{C}$ no ductility was dimpled ductile frava facets evident over the whole of the fracture surfaces. Above $-120^{\circ} \mathrm{C}$ purely as the tempere is illustrated in Figue $-180^{\circ} \mathrm{C}$ and $-120^{\circ} \mathrm{C}$ the amount of ductility increase. Thu $150^{\circ} \mathrm{C}$ red in Figures $2 \mathrm{a}$ and $2 \mathrm{~b}$ which show the fracture surfaces of samples tested $\mathrm{at}-130^{\circ} \mathrm{C}$ . Clearly

To assess the reproducibility of the fractographic observations, the behaviour of disks tested inder imilar conditions were studied. It was found that in the fully be the behavis of disks tested under appearance of the fracture surfaces was very reproducible brittle and fully ductile conditions the samples with mixed failure modes. Thus, for topts transition range variations in the degree of ductility undertaken at one temperature within the hat these variations were a consequence of in samples which contained relatively contained non metallic inclusions. Figure 3 . Chounts of ductile fracture many of the dimples of two types; Manganese therefore appears to be a suphide and Silicates. The observed variation in fracture behaviour the distribution of inclusions as noted from the

\section{Fracture energy}

Fracture energies produced from Charpy tests over a temperature range of $-32^{\circ} \mathrm{C}$ to $+140^{\circ} \mathrm{C}$, exhibited a change from low to high energy as the temperature increased. Below $02^{\circ} \mathrm{C}$ to $+140^{\circ} \mathrm{C}$,
lessies of increased from 45 to $150 \mathrm{~J}$. At higher temperatures the fracture 0 a slower rate until eventually at +140 . $\mathrm{C}$ a maximum frature energy continued to increase but at whole test range the fracture energy varied from 2.5 to $160 \mathrm{~J}$. Fig was reached of $160 \mathrm{~J}$. Over the

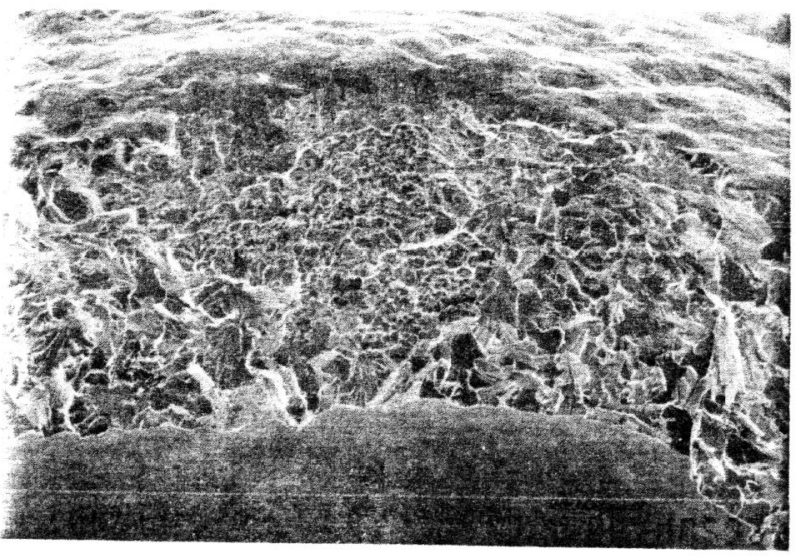

Figure 2a. Typical micrograph of the fracture surface for tests at $-130 \mathrm{C}$.

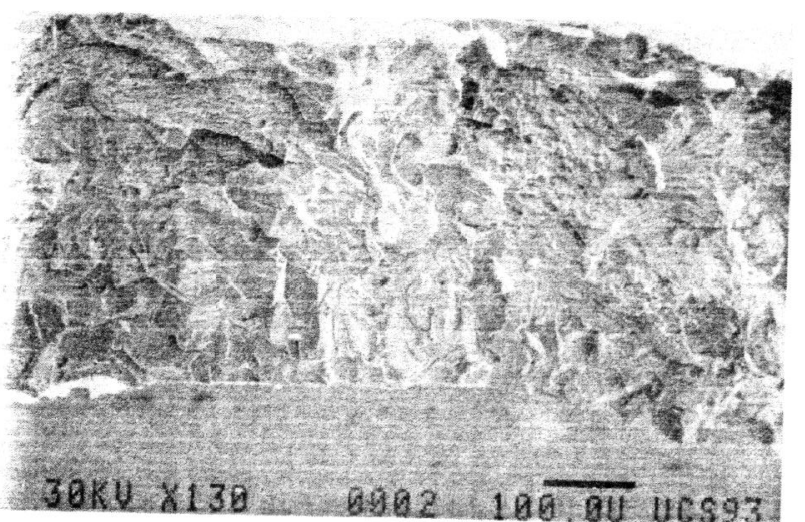

Figure $2 \mathrm{~b}$. Typical micrograph of the fracture surface for tests at -150 'C

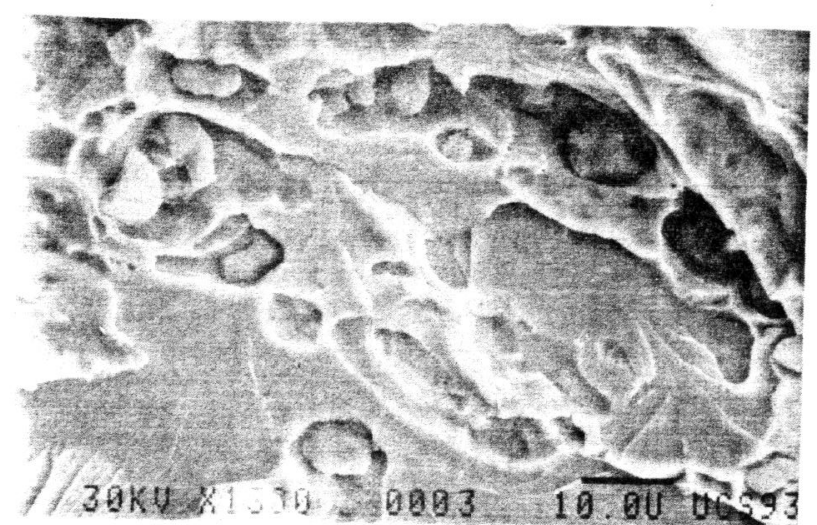

Figure 3. Detail of the dimpled fracture and associated inclusions 
For each disk test, an estimate of the fracture energy was made from the load displacement curves. The fracture energy was taken to be the area under an individual load displacement curve up to the point of maximum lod. Average frathe point individual tests and plotted against the relevant temperature, Figure 4 . It was found that at very low temperatures, ie the brittle failure region below $-180^{\circ} \mathrm{C}$, low fracture energies were produced, $0.3 \mathrm{Nm}$ or less. As the temperature increased between $-180^{\circ} \mathrm{C}$ and $-120^{\circ} \mathrm{C}$, ie the transition region, a sharp increase in the fracture energies was observed. Thus an increase from about 0.3 to $1.4 \mathrm{Nm}$ was noted over this temperature range. Above $-120^{\circ} \mathrm{C}$, where the disks behaved in a fully ductile manner, the average fracture energies were fairly constant. Over the whole test temperature range the fracture energy changed by approximately $1.2 \mathrm{Nm}$.

For each group of four or five tests performed under similar test conditions, a certain amount of data scatter was observed, Figure 4 . The scatter in the fracture energies was most marked in the high energy region of the graph, ie above $-120 \mathrm{C}$, where energy differentials of up to $0.6 \mathrm{Nm}$ were evident. In the transition region, between $-120^{\circ} \mathrm{C}$ and $-180^{\circ} \mathrm{C}$ data scatter was significantly reduced between $-120 \mathrm{C}$ and $-180 \mathrm{C}$ dat scat in the differences in energy were only 0.1 to $0.2 \mathrm{Nm}$.

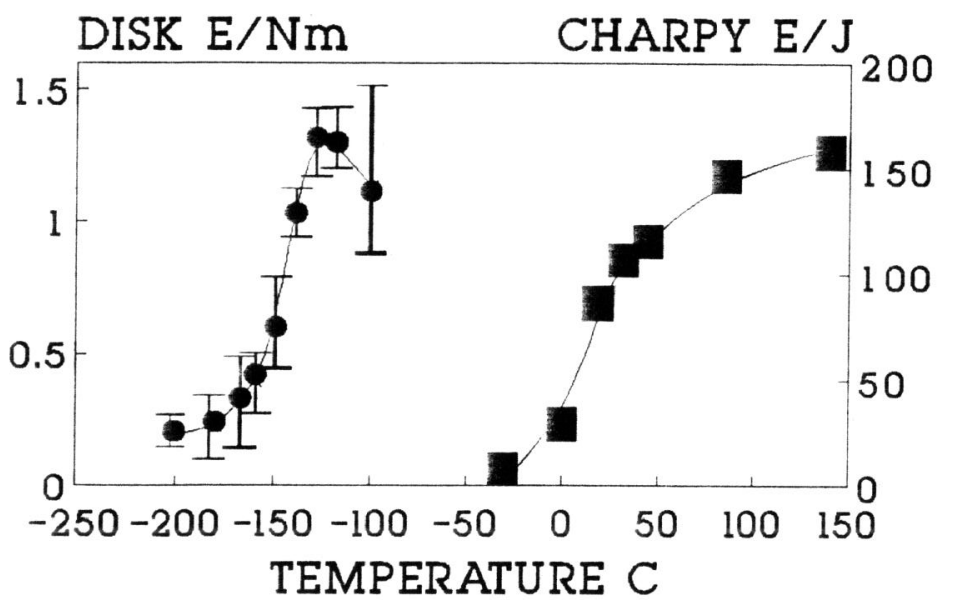

Figure 4. Variation of disk and Charpy fracture energy against test temperature.

\section{DISCUSSION}

The load displacement behaviour observed was dependent on a balance between deformation and fracture characteristics. Thus, variations in behaviour can be explained in terms of test temperature and details of the constituent microstructure. Tests at room temperature showed a large amount ductility, with three distinct regions of behaviour. Initially, the disk deformed elastically unt vielding wocred. Due to a non uniform stress distribution th the punch tip, yielding oceurtly yielding occurce. Due to a non uniform stress distribution at the punch tip, yielding occurre gradually. The yield frent then noved thatly outward deformation predominated, with work hardening leading to a steady load increase. This steady period is known as 'membrane stretching ${ }^{\prime\{1}$, continued until the maximum load was reached. Finally the specimen became dimensionally unstable and fracture, indicated by a significant load drop, followed.

At very low temperature, below $-180^{\circ} \mathrm{C}$, macro ductility was not observed on the fracture surfaces. Under these conditions the stress required for plastic deformation is high so that initiation of microdefect resulted in rapid brittle crack propagation through the ferrite matrix. Non metallic inclusions appeared to play no part in this process. As the test temperature increased the critical crack size became larger. The stress field ahead of the cracks caused plasticity and the zone of plastic deformation interacted with non metallic inclusions to form voids. Deformation then caused the ligaments between the newly formed voids to neck down and link up leading to regions of dimpled rupture ${ }^{[6]}$. Within the transition zone ductile fracture extended until a critical defect size was attained, leading to rapid fracture. At the highest test temperatures the relatively large critical crack size combined with a relatively low yield stress, resulted in significant plasticity through the size con and a fully ductile frot It appears that the prese zone of an individual defect was therefore respo promoting crack blunting. Thus, it appears that the scatter in fracture energy at a given test lemperature was related to the level of inclusions present within the zone of plasticity at a crack tip. For a series of tests at the same temperature the material in each disk did not have identical inclusion profiles, as shown by the metallographic characterisation. For one such test, if the advancing crack encountered no inclusions in it's stress field, the crack remained relatively sharp and on reaching a critical size, rapid brittle fracture occurred. If, on the other hand the crack encountered a region of inclusions inside it's stress field, the ductile process of void formation took place. This effectively blunted the advancing crack and increased the amount of energy required to make the crack grow further. Scatter increased with temperature as a consequence of the decrease in the yield strength, in view of the increase in the plasticity at relatively high temperatures a greater proportion of the disk, had a bearing on the fracture process. As the inclusion profiles were far from uniform throughout the material a larger volume of material involved in fracture increased the probability of scatter.

The variation of fracture energy with test temperature for the disk samples and from the Charpy tests are shown in Figure 4 . It is clear immediately that the transition from high to low fracture energy for the disk tests occurred at a much lower test temperatures than for the V-notch impact test. What is also clear is that the transition in the disk specimens occurs over a much narrower temperature range, in the region of $60^{\circ} \mathrm{C}$, compared with a transition over approximately $120^{\circ} \mathrm{C}$ for the Charpy test. From these curves it is possible to quantify the respective transition temperature. For the disk tests, a transition temperature corresponding to a point at $50 \%$ of the energy range, was estimated $-146^{\circ} \mathrm{C}$. The $50 \%$ FATT value calculated from the Charpy tests was $34^{\circ} \mathrm{C}$

The results have shown that the $50 \%$ FATT produced by the impact tests was much higher than the $50 \%$ DBTT produced by the disk samples. The test techniques varied in two distinct areas, and this variation appears to be responsible for the differences in the observed data. Firstly, the y-notch manufactured in the impact bars produced triaxial constraint in the material behind the notch. This manufactured in the impact bars produced traxial constraint in the material behind the notch. This effective size of the plastic zone size that condly for impact specinen in particular the contrained nue to the nature of the test.these rapid loading rates also promoted brittleness. The disk test however, produced a biaxial loading system. There was no constraint in the thickness direction of the disk due to it's small dimension and the absence of a notch. A very much lower loading rate was also used for the disk test. These two differing factors meant that material tested via the disk test route exhibited ductility at much lower temperatures than material tested via the impact test route. 


\section{CONCLUSIONS}

The miniaturised disk bend test described has great potential for examining the deformation and fracture behaviour of materials used in structurally critical components. The test program and demonstrated that credible load:displacement data can be produced over a wide range of temperatures. As the temperature is changed, sensible variations in deformation and frecture behaviour were observed. The energy and displacement to fracture underwent a sharp transition fro high to low values, as the temperature is decreased. This indicated a sharp change in the fractor behaviour of the disk specimens. The variation of fracture energy with temperature Figure 4 , bas been shown to be similar in form to a Charpy transition curve. Due to differences in Figure 4, has loading conditions, the DBTT is much lower than the FATT. However, it is posibleometry and data from the two different test techniques, and a Fut. possible correlations are bein

Sensible trends from the fracture surface studies, have shown that the amount of observed ductility the energy of the tests. Fracture energy as also been explained using the fracture surface studies.

\section{ACKNOWLEDGEMENTS}

One of the authors (SDN) is grateful to the Science and Engineering Research Council and Powergen Plc. Ratcliff for financial support.

\section{REFERENCES}

I. Yu, J and McMahon, C.J. "The effects of composition and carbide precipitation on temper embrittlement of $2 \frac{1}{4} \mathrm{Cr} 1 \mathrm{Mo}$ steel" Part 1 Effects of P+Sn, Met Trans vol,11 A,1980 227-235.

2. Parker, J.D. and Bisbee, L.H. "Monitoring the in-service changes in material properties", Semin Acceptance Testing and monitoring of steam plant, Institute of Mechanical Engineers, 1991.

3. Mao, X. and Kameda, J. "Small punch technique for measurement of material degradation of irradiated ferritic alloys", Journal of Materials science, 26, (1991) 2436-2440.

4. Foulds, J.R, Jewett, C.W, and Viswanathan, R. "Miniature specimen test technique for FATT", Electric Power Research Institute, 1991.

5. Baik, J.M, Kameda.j and O.Buck. "Development of small punch tests for ductile-brittle transition temperature measurement of temper embrittled $\mathrm{Ni}$-Cr steels", American Society for testing and
materials. Philadelphia, 1986, pp 92-111. 6. Knott, J. "Micromechanisms of fibrous crack extension in engineering alloys", Metal Science,
$1980,327-336$ 